\title{
Villages, Customary Laws and Community Management of Ethnic Minority Groups in the Central Highlands
}

\author{
Tuyen Mong Thi Nguyen (Corresponding author) \\ Department of Political Theory, Open University Ho Chi Minh City \\ 97 Vo Van Tan, 6th Ward, 3rd District, Ho Chi Minh City, Vietnam \\ Tel: 84-91-316-18171Ｅ-mail: tuyen.ntm@ou.edu.vn
}

Received: October 8, 2019 Accepted: October 28, 2019 Published: November 23, 2019

doi:10.5296/ijch.v6i2.15593 URL: https://doi.org/10.5296/ijch.v6i2.15593

\begin{abstract}
Vietnam has been fundamentally an agricultural country and consequently, rural areas with farmers play a critical role in its socio-economic development. As villages and communes are foundational social structures of the agricultural society, they have been the focal points in the development process throughout the history, especially during the modernization and industrialization of the country. For ethnic minority groups in the Central Highlands, despite their relative low socio-economic development level, the social relations are community based, which forms the potential strength of the nation. Socio-economic development and village management have become central tasks set forth by the Party and the national government of Vietnam. The goals are to foster the development of the Central Highland villages while protect them from adversary derivative conditions, creating prerequisite conditions for the region's integration with the market economy that is being formed and developed. With the development trend, the tools for managing and regulating basic social relations are customary laws and State laws. In this paper, we discuss a traditional form of society which is the village and its customary laws as solutions to developing advanced social relations, enhancing the internal power of the region, creating a driving force for the country.
\end{abstract}

Keywords: Customary laws, Traditional rules, Ethnic groups, Culture, Central highlands 


\section{An Overview of the Origins of Indigenous Ethnic Groups in the Central Highlands}

\subsection{Geographical Location and Name}

The Central Highlands constitutes a range of adjacent highlands in the middle region of Vietnam, divided into five provinces, namely Kon Tum, Gia Lai, Dak Lak, Dak Nong, and Lam Dong. This region borders lower Laos and Northeastern Cambodia to the west, Quang Nam province to the north, Quang Ngai, Binh Dinh, Phu Yen, Khanh Hoa, Ninh Thuan, Binh Thuan, Dong Nai to the east and Binh Phuoc to the south.

The Central Highlands have undergone significant changes, especially during the war and been referred to by different names: Les Hauts Plateaux du Sud under the French colonialism (translated as Tay Nguyen - Southern Highlands), or Cao Nguyen Trung Ky (Central Highlands) by Nguyen dynasty - as this land was supposed to be part of Upper Highlands, an administrative unit under the Central region of Vietnam. After that, Tran Trong Kim's government renamed it to Cao Nguyen Trung Bo (The Middle Highlands), which was later changed into Hoang Trieu Cuong Tho (Royal Border Land) under Bao Dai reign. This area was affiliated with the Middle Region to become "Middle Region's Highland" until 1975. According to another reliable source, the Central Highlands were officially mentioned in the Constitutions of Vietnam Republic declared in 1960 (Nguyen, 1999), in which there was an article about the sovereign of minor ethnic groups, including the Central Highlands. Central highlands had the total land area of $54,508 \mathrm{~km} 2$, and the population of 5,693, with a density of 104 person $/ \mathrm{km} 2$.

\subsection{Communities and Cultural Identities of the Central Highlands' People}

Archeological evidence shows the Central Highlands is an ancient cultural area with traces of human presence since the New Stone age, reaching a high level of civilization and this region underwent several upheavals due to the war. According to different sources, before the French colonialization, the Central Highlands used to be a sovereign zone with massive land area and low population density, with self-governed minor ethnic groups who had suffered from the devastating wars with Champa or Chan Lap kingdoms. In the XVI-XVII centuries, native people known as Moi Da Vach (Hre), Moi Hoi (Hroi, Kor, Bru, Ktu and Pacoh), Moi Da Ham (Djarai), Moi Bo Nong (Mnông) và Bo Van (Rhadé Epan), MoiVi (Raglai) và Moi Ba Ria (Ma), etc. were living in this region, under the protection of Nguyen kings. After several decades, the Central highlands received more ethnic groups from the Centre and the North of Vietnam, including Tay, Thai, Nung, Muong, H'mong, Dao and Viet. According to Prof. Ngo Duc Thinh - Director of Centre for researching and conserving Vietnam's religious beliefs there are above 40 ethnic groups, including 20 indigenous ethnic groups, creating an area of cultural diversity, fusion, interchange, and mutual influence. The region also witnesses the disjunction between the tradition and the modernity.

In 1858, the French colonists launched armed attack in Vietnam. By 1884, with different military and political measures, the French had colonialized the Central Highlands, establishing administrative units to isolate this region from the plains, exercising the policy "Dividing for Governing". This is among the reasons explaining why the Central Highlands 
developed "forest culture", "botanical culture", or "village culture", and the communities confine themselves in small-scale localities, forming a more "intangible culture" rather than "tangible culture".

Indigenous people from the Central Highlands have "realistic- visionary" mindset; realistic in the sense that all things are often referred to natural phenomena, animals and plants; visionary in the sense that all the natural phenomena carry in them the "Yang" (spirit), making the materialistic world have the soul. Humans are part of nature, existing equally and connected with nature to create profound humanity (Ngo, 2013).

The language spoken by Central highlands' people is highly imagery and rhythmic, intermediate between the daily language and literary one. Gong is also a language for communication, expressing the connection between human beings and supernatural forces. This distinct form of communication contributes to the rich, unique culture identity of the region. Hundred pieces of gong music emanating from prehistoric stone flats possessed by the indigenous people are viewed as the most precious properties in the world. On $15^{\text {th }}$, November 2005, UNESCO recognized "Gong cultural space in Central Highlands is an oral and intangible heritage of human kinds". Another cultural trait of the Central Highlands is customary laws in the form of oral verses, which contain knowledge about community management and rich cultural identity of each ethnic group, handed down from generations to generations, along with more than 20 "epics" of different tribes. The Central Highlands' epics are stored in the people's memory and performed in communal events. In addition, there are masterpieces of sculptures, tombs, architectures, fine arts, and communal long houses along with folklore belief system and festive customs, forming the tangible and intangible cultures of each tribe and village.

Due to the historical and cultural impacts, the Central Highlands are characterized by isolation, enclosure, conservativeness of the traditional village socio-economic structures, with a low level of development. Economic self-sufficiency, political autonomy, and homogenous culture are three factors circumscribing the villages' economy, which is highly primitive, where main livelihoods are hunting, gathering, production using rudimentary means, and natural exploitation. Being sparsely populated, difficult terrains, poor transportation and absence of economic exchange are major barriers for the socio-economic development of the region. The residents almost "lived a life outside the development", being enclosed in the villages, which formed a standstill society during the period from pre-war to post-war in Vietnam.

Approaching the national economic development models, the Central Highlands' economy is a "focal point" between the traditional (backward) and the modern (progressive). In order to bridge between the traditional and the modern, to bring the Central Highlands to a higher level of socio-economic development comparable to the North and the South, there have been bold and rigorous policies from the central government. These policies, however, have met with numerous daunting challenges and adversities, with some being failures. Nevertheless, the Central Highlands has enjoyed striking economic development on their way to integrate into the national socio-economic development, blurring the differences. 
Vietnam has gone through upheavals and conflicts due to its strategic location in the "political geographic area". Today, with the global trend, Vietnam is undergoing modernization and industrialization with socialist orientation, and villages have become the "bridging point". Community social relations, as the distinct feature of the Central highlands despite a low level of socio-economic development, are the potential strength of the nation. Socio-economic development and village management have become central tasks set forth by the Party and the national government of Vietnam. The goals are to foster the development of the Central Highland villages while protect them from adversary conditions, creating prerequisite conditions for the social structure there to gradually integrate with the market economy that is being formed and developed. With the popular development trend, the tools for managing and regulating basic social relations are customary laws and State laws. In this paper, we discuss a traditional form of society which is the village and its customary laws as solutions to developing advanced social relations, enhancing the internal power of the region, creating a driving force for the country.

\section{Situations and Proposed Solutions}

\subsection{Villages - Social Organizations of the Central Highlands}

Villages and community cohesion: Villages are the basic organizational structures of an agricultural society, where inhabitants cluster and live in a simple, natural environment. For subsistence purpose, villages become a social and economic organization with close community culture. The Central Highland's village organizational structures and community cohesion have the following bases:

The Central Highland's villages are communities of inhabitants or households. Natural environment and farming land naturally attract families of different sizes to come and live either in private houses or in the communal, long houses. These families follow either matriarchal or patriarchal system, living in the crescent area within or around the communal house, a feature of the blood- related communes in the old days. The forms of inhabitation as well as social relations have recently been transformed into neighbor-based commune. Since 1975, as a result of the government's policy for developing horticulture, the long communal houses have been divided into smaller houses for nuclear families, a major breakthrough in accelerating the breakdown of blood-related communes.

Community cohesion also depends on lands, forests, forest lands - watershed forests and watershed rivers - favorable natural conditions of the Central Highlands. However, the wars and the growth of population following the government's policy for building new economic zones have drastically changed the villages and their institutions.

Villages as communities of ownership and interests: Forests and forestland are owned by the public and thus each inhabitant has the right to claim forest land for farming. This is explicitly stated in the customary laws of the Central Highlands' people. For example, Ede's customary law has it that:

"Land, rivers, and forests are handed down by our forefathers, 
When the uncle passes away, they are handed down to the nephew,

When the grandmother passes away, they are handed down to the grandchildren,

When one passes away, they are left for others

No one can take over,

No one can appropriate by any means"

As public possession is stated in the customary laws, everyone can use:

"Everyone of us has the right to burn the farm and catch fish,

Everyone of us has the right to climb the trees to get honey,

Le trees, Lo o trees, and bamboos are used to make houses; Everyone of us has the right to obtain,

Everyone of us has the right to burn forest to clear land for farming, to hunt wild animals and to catch fish..."

The Central Highlands' traditional societies have existed no private ownership of land and natural resources, trading and transferring of capitalist document. Disputes over land and forest are few; and if any, they are resolved using customary laws. For example, if a family claims a patch of land from forest for a harvest or two, then stops for a while for the land to recover, they will have certain rights over that patch. Anyone who wishes to farm on that land patch needs to obtain permission from them.

The coexistence of public ownership and privatization of public properties has given rise to conflicts in the traditional agricultural society. In addition, migratory population growth and underdeveloped infrastructures have resulted in higher population density, land scarcity, the depletion of forest, and degradation of fertile land since 1986. Besides, the impacts of market economy, especially the commercial farming of industrial trees such as tea or coffee, etc., have complicated the transfer and trading of land. Previously, as the villages were the sole owners and managers of land properties and natural resources, only their inhabitants had the right to appropriate land whereas outsiders could not claim, transfer, buy or sell land; disputes over land were rare. Today, the new Land Law issued by the government, public ownership of land is no longer valid; land and natural resources are therefore not the properties of any one so the appropriation, trading and transfer of land have become complicated. The villages become crowded and the forest and ecosystem are degraded as a consequence.

After the State government regulated the nationalization of land properties, millions of forest hectares in the Central Highlands have been logged, according to a recent study. Forest exploitation has become uncontrolled. As a result, cultural foundation, social structures, traditional rituals and customs, knowledge and self-esteem of the minor ethnic people have been ruined. Most of the cultural features, religions and religious activities have been eradicated (Dang, 1986). Community has been replaced by cooperatives; nuclear families have taken over extended families. Long communal houses have gradually disappeared. 
Cultural interruption has deteriorated the functions of traditional institutions.

After 1990, the government eliminated the cooperative production model, releasing land and forest to people based on the market mechanism. In the Central Highlands, forest started to be handed to the mass to use and manage. Market economy in this region developed vigorously and thus come free migration. More than 2.3 million people migrated to Central highlands (late 1980s). During the 1990s, this region received more than 300,000 people every year. Migrants are not only Kinh people, but other ethnic people from the North such as Tay, Nung, Hmong, Thai, Dao. As a consequence, forest has been destroyed in various places.

The most obvious change in the Central Highlands is the development of infrastructures and utilities, modern cities and town by Kinh people, who accounted for a large majority of the population. Yet most of indigenous people are still living in poverty in remote areas. The Central Highlands has the highest rate of poor ethnic people, accounting for $38 \%$ and thus the largest gap between the rich and the poor (Le \&Vu, 2004; Truong 2004; Thanh Nien, 2005). With more than 5.5 million people belonging to 45 minor ethnic groups living together, the Central Highlands is facing daunting challenges in managing the society and environment.

Villages as spiritual communities, exhibiting in religious beliefs, ceremonies, and rituals, etc. which are the elements that join people around sacred spiritual symbols, supernatural forces which formulate "soft power" to protect them before threats and risks in real life. This could be explained by the fact that people in the Central Highlands used to live in the heavenly and spiritual world, creating a mythical atmosphere. On the other hand, it is the "mystic realities" that contribute to the unique indigenous culture, literature and arts of the region, forming the "soft power" of the nation.

Villages as cultural communities. Villages, originally communities of residence, ownership and interest, have gradually become cultural communities, manifesting the homogeneity in a range of rituals, customs, ceremonies, events, and equal, democratic social relations. Like spiritual communities, cultural communities are cohered by invisible ties, lasting from generations to generations. Customs and rituals have set in people's ways of living, unconsciously and who deviate from these norms are criticized by the community, or even convicted by customary laws.

Along with their socio-economic development, the Central Highlands' villages has experienced significant changes toward more progressive and modern culture. Backward customs such as Malai (beliefs about ghostly evils), Chue nue (a marital ritual), and mass burying of dead people have been eliminated. New cultural forms have been established based on the exchange among ethnic groups, while long-lived cultural traditions have still been preserved by the ethnic people, with the assistance of the Party and the government. Promoting a cultural village means creating a cultural community where the tradition and the modern are infused.

In a nutshell, villages in the Central Highlands are by nature communities of inhabitation (co-habitation), communities of ownership and interests (co-interest), communities of spirit (co-fate), and communities of culture (co-feeling). These form the "soft power|" and "hard 
power" of a nation and its people.

\subsection{Customary Laws - Conventions and Community Management in the Central Highlands Today}

\subsubsection{Customary Laws}

Customary laws are among the cultural heritages, containing folk knowledge about community management of ethnic groups in the Central Highlands. Most indigenous peoples such as Ede, M'nong, Giarai, Bana, Xtieng, Ma, Sre, etc. have customary laws. The customary laws of the Central Highlands exist primarily in oral forms, which are highly imagery, referring to all areas of social life such as the leader and the relationship between the leader and the community, marriage and family relations, customs and social relations in the village, ownership of land and resources, offences against individuals (scolding, beating, killing people, etc.) rituals and beliefs, etc. These customary laws are interwoven with the Kinh people's conventions, so the customary laws of ethnic minorities in the Central Highlands have a significant role as a tool to manage villages from the past to the present.

The customary laws of the Central Highlands differ from state laws in following aspects:

Firstly, customary laws are intermediaries between customs or traditions and state laws, so it can be seen as a pre-law form, which is suitable for small communities with low social development levels.

Secondly, as customary laws are integral to a culture, people implement customary laws voluntarily as a cultural behavior. That makes the law-obeying culture, constituting the power of customary laws.

Thirdly, customary laws are often localized, distinct in specific localities and ethnic groups. They are the agreement of the community on appropriate social norms and principles in accordance with community benefits and cohesion, so they mutate with social change. In the globalization today, customary laws of the Central Highlands are also changing.

Fourthly, in implementing customary laws, the basic principle is how to ensure the unity and cohesion within the community, rather than just the fairness between the two sides having conflicts like as in implementing State laws.

In the Central Highlands today, customary laws and state laws are both implemented in community management. However, differences or even contradictions in these two types of laws often lead to conflicts.

\subsubsection{Community Conventions}

Community conventions in the Central Highlands today have been regulated by Decision 22/2018/QĐ-TTg of the government on developing and implementing conventions. Accordingly, community conventions have to align with the following principles:

- In accordance with the Party's guidelines; policies and laws of the State; social ethics, customs, and good practices of the community. 
- Ensuring voluntariness, based on the agreement of the residential community; fully promoting the ownership of people; based on self-governance needs of the community.

- Protecting, preserving and promoting traditional cultural values; building new cultural values appropriate with the specific community.

- Do not violate human rights, civil rights, and gender equality.

- Fees, charges, fines, or penalties are not applicable.

\section{Discussion and Recommendations}

Villages are the basic social organization structure of indigenous ethnic groups in the Central Highlands. A village today is a thread connecting the traditional and the modern, the past and the present - future, so it plays a pivotal role in the economic, social, cultural and national security development in the Central Highlands. Accidentally or intentionally breaking and upsetting the village social structure will demotivate and deteriorate the internal resources for the development process in the Central Highlands.

Community is an inherent and intrinsic attribute of ethnic minority villages in the Central Highlands, especially for ethnic groups who are still at a relatively low level of social development. Community is constructed in different senses: the residential community, the community of ownership and interests, the spiritual community and the cultural community. During the long-term development process, despite significant changes in this community base, community cohesion is still a force that can either promote or inhibit development in the context of internationalization and globalization.

In the traditional society of the Central Highlands' ethnic groups, one of the most important tools for managing and regulating social relations in the community is customary laws. Currently, although there have been changes in the minor ethnics' society and the State laws have been gradually adjusted and taken effect, customary laws and community conventions still play an important part in community management, especially in conceptualizing social relations, building healthy culture, and preserving fine traditions and customs.

Restoring customary laws in the villages is a sensible policy of our Party and the government. The development of new community conventions should inherit the traditional community management knowledge. Particularly, following knowledge areas should be taken into account: firstly, ownership relations and the management of exploitation and handling of natural resources; secondly, building harmonious and healthy social relations, especially family and neighborhood relations. Moreover, it is important to inherit and promote fine cultural traditions, build new cultural villages and enrich cultural life at the grassroots level.

The development of new conventions should also incorporate new elements appropriately, ensuring both nationalism and democracy in order to promote the dynamism, creativity and the democratic rights of the people, avoiding impatience and rigid imposition of laws and conventions. In the implementation, there must be inter-ministerial, inter-sector and inter-department cooperation to avoid local, overlapping, duplicating programs and 
guidelines.

Hereby, we would like to offer our views of long-term solution, specifically as follows:

Perfecting mechanisms and policies and laws, creating special urban economic zones for the Central Highlands.

Decentralization is one critical measure to guarantee the effective administration and socio-economic management in specific localities.

The key cadres of the provinces must ensure quick, efficient and effective management and administration; upholding the individual responsibilities. It is important to have an effective mechanism to supervise the heads of key economic administrative units in order to avert the abuse of power; promptly detect and prevent decisions not in compliance with law provisions. The principle is to ensure the leadership of the Party; the supervision of the municipal People's Council; the direction of the government, the Prime Minister, concerned ministries and ministerial-level agencies, municipal People's Committee and its chairman.

Effectively enforce the laws on natural resources and environment, and apply rigorous management and protection of natural resources in mountainous and border areas.

Complete policies on business investment, infrastructure development, investment support services, investment incentives, land, labor, attraction of foreigners; import and export, etc.

\section{Developing urban road systems according to international standards}

Since the Central Highlands needs space and resources to ensure sustainable socio-economic development in the future, the local authorities in particular and the state government in general need to set up schemes, surveys, and architectural planning to urbanize villages and districts and to build transport infrastructure up to international standards and to construct high-quality resorts to attract tourists to natural beauty spots.

On the other hand, main roads passing through complex terrains such as mountain passes must have tunnels through mountains to avoid traffic accident risks.

Expand and upgrade belt roads in the traffic network for each province in order to serve the overall socio-economic development and meet the needs of eco-tourism development in each locality.

At present, the traffic system in the Central Highland is very poor; roads in residential areas and villages are often narrow or just in the form of trails, so they must be upgraded or new roads must be built to create favorable traffic conditions. Favorable traffic conditions will facilitate exchange, trade and thus develop the economy. Every year, provinces should co-provide training and retraining courses about tourism knowledge (skills, trade ...) for officials and people in the area.

In the long run, the Central Highlands should develop railways and highways (freeway) connecting the midpoint of the southern and northern regions to expand trade between regions. 
One of the 5-year national goals for development, during the period 2016-2020, stated in the Resolution of the 12th Party Congress of the Party is: "to practise uniform mechanisms, policies and solutions, measures to develop human resources, especially high-quality manpower, to meet the requirements of socio-economic development".

The question is how to assess the current training and development quality to propose effective solutions, meeting the requirements of industrialization, modernization and international integration. The documents of the 12th Congress of the Party stated: "Build a strategy for developing human resources for the country, for each industry, each field, with uniform solutions, focusing on training and retraining of human resources at school as well as at work, improving professionalism and practical skills. Develop all kinds of non-public schools for vocational education and higher education in an appropriate way". Therefore, in order to have sufficient human resources for socio-economic development in the five Central Highlands provinces, it is necessary to have an autonomy mechanism which allows them to prepare their own projects and implement specific policies on education investment and training of high-quality human resources to meet the requirements of economic development to the regional level.

\section{Planning for tourism - service development}

One potential solution is prioritizing the investment in and exploitation of eco-tourism and other tourist services distinct for the Central Highlands. First of all, build green parks, protecting, restoring and developing ecological forests for developing tourism, composition, scientific research, international conferences, etc.

It is also important to build and exploit indigenous "gong" and "long communal houses" cultural heritage zones, etc. to serve as places for mainstreaming the education of revolutionary traditions for teenagers, students, and pupils and to attract domestic and foreign visitors.

Another measure is to construct amusement and entertainment parks and eco-tourist areas in order to promote sightseeing tours and long stays.

\section{Urbanization of rural areas and renovation of agriculture}

In addition to exploiting the potentials of ecotourism, the Central Highlands needs to develop urban-oriented agricultural production in a sustainable manner; applying scientific and technological advances to enhance productivity, efficiency, thus raising people's incomes and reducing poverty sustainably. Besides, it is important to promote cultural and spiritual values, protect the ecological environment; build a transparent and solid political system; ensure social security in order to develop a civilized, modern and friendly Central Highlands.

Another solution is to enhance research in, transfer of or investment in advanced science and technology to deal with environmental pollution, respond promptly to climate change, and develop sustainable agriculture. Develop potential field survey projects or projects that promote high-end entertainment activities such as international "gong" cultural festivals, indigenous cultural exhibitions, etc. in order to boost Vietnam's tourism development. 
On the other hand, shortly implement specific projects: health care for the elderly, spiritual tourism, artificial waves, nightlife, re-enacting the ancient cultural space; film studio for training and employing local laborers ...

Construct an international-standard tourist and resort urban center while prioritizing environmental protection because this area contains forest land and national resources. Therefore, it is requisite to formulate special urban planning with a long-term vision so that the Central Highlands reserves its traditional beauty with a modern muse, ensuring nationalism and democracy.

\section{Conclusion}

It is imperative to tap into the strategic potential of the Central Highlands and propose further solutions for developing its socio-economy. The aforementioned solutions and recommendations, among others, will bring into full display the strengths of the Central Highlands, making significant changes for the region in the industrialization and modernization period. Identify the needs of both domestic and foreign tourist businesses, make a statistics of the labor population, and focusing on tourism in order to have training and retraining plans for the labor force to meet the development needs. Promoting economic development and improving the living standard of people in the Central Highlands are requisite to awaken the strategic potential of the Central Highlands in particular and for the country in general in the future.

\section{References}

Dang, N. A. (2015). Population and migration in sustainable development in the Central Highlands. Hanoi: Institute of Research for Socio-economic Development.

Dang, N. V. (1986). Some fundamental and urgent socio-economic problems in the Central Highlands in the first phase of transition into the socialism. Some socio-economic problems in the Central Highlands. Hanoi: Publishing House of Social Sciences.

Dang, T., \& Le, D. D. (1986). Demographic briefs of the Central Highlands' population. Some socio-economic problems in the Central Highlands. Hanoi: Publishing House of Social Sciences.

Hardy, A. (2002). Red hills: migrants and the state in the highlands of Vietnam. Honolulu: University of Hawaii Press.

Jamieson, N. L., \& T. C. Le, T. C. (1998). The development crisis in Vietnam's mountains. Honolulu: University of Hawaii Press.

Le, D. Q., \& Vu, H. P. T. (2004). Cultural life of some minor ethnic groups in the Central Highland. In T. V. Binh (Eds.), Cutlure of the Central Highlands' Peoples - Situations. Hanoi: National Political Publishing House.

Luong, T. T. H., Phan, T. G., \& Truong, Q, H. (2015). A study on customary laws of minor ethnic groups and policies on forest land in Vietnam. Retrieved from https://data.opendevelopmentmekong.net 


\section{Macrothink}

International Journal of Culture and History

ISSN 2332-5518 2019, Vol. 6, No. 2

Ngo, D. T. (2013). Conserving and promoting traditional culture of the Central Highland's ethnic groups. Hanoi: Institute of Research for Socio-economic Development.

Nguyen, D. T. (1999). The Central Highlands in the past and present. Journal of Past and Present, No.61B.

Nguyen, T. T. (1986). Fundamental guidelines in economic development in the Central Highlands. Some socio-economic problems in the Central Highlands. Hanoi: Publishing House of Social Sciences.

TCTK. (2016). 2016 average population by localities. Hanoi: General Department of Statistics.

Thanh Nien. (2005). Five growth patterns that should be averted. Thanh Nien Newspaper May 4, 2005.

UBDT. (2013). Categories of ethnic and mountain territories according to development level, 2012-2015 period. Hanoi: Ethnic Committee.

\section{Copyright Disclaimer}

Copyright reserved by the author(s).

This article is an open-access article distributed under the terms and conditions of the Creative Commons Attribution license (http://creativecommons.org/licenses/by/3.0/). 